Zhao, O., Afshan, S., \& Gardner, L. (2017). Structural response and continuous strength method design of slender stainless steel cross-sections. Engineering Structures; 140: $14-25$.

\title{
Structural response and continuous strength method design of slender
}

\section{stainless steel cross-sections}

\author{
Ou Zhao ${ }^{* a}$, Sheida Afshan ${ }^{\mathrm{b}}$, Leroy Gardner ${ }^{\mathrm{c}}$ \\ ${ }^{a}$ School of Civil and Environmental Engineering, Nanyang Technological University, 50 Nanyang \\ Avenue, 639798 Singapore, Singapore \\ ${ }^{\mathrm{b}}$ Department of Mechanical, Aerospace and Civil Engineering, Brunel University London, London, \\ UK \\ ${ }^{\mathrm{c}}$ Department of Civil and Environmental Engineering, Imperial College London, London, UK \\ * Corresponding author, Phone: +65 67906934 \\ Email: ou.zhao@ntu.edu.sg
}

\begin{abstract}
In current structural stainless steel design codes, local buckling is accounted for through a cross-section classification framework, which is based on an elastic, perfectly-plastic material model, providing consistency with the corresponding treatment of carbon steel cross-sections. Hence, for non-slender cross-sections, the codified design stress is limited to the $0.2 \%$ proof stress without considering the pronounced strain hardening exhibited by stainless steels, while for slender cross-sections, the effective width method is employed without considering the beneficial effect of element interaction. Previous comparisons between test results and codified predictions have generally indicated over-conservatism and scatter. This has prompted the development of more efficient design rules, which can reflect better the actual local buckling behaviour and nonlinear material response of stainless steel cross-sections. A deformation-based design approach called the continuous strength method (CSM) has been proposed for the design of stocky cross-sections, which relates the strength of a cross-section to its deformation capacity and employs a bi-linear (elastic, linear hardening) material model
\end{abstract}


to account for strain hardening. In this paper, the scope of the CSM is extended to cover the design of slender stainless steel cross-sections under compression, bending and combined loading, underpinned by and validated against 794 experimental and numerical results. The proposed approach allows for the beneficial effect of element interaction within the crosssection, and is shown to yield a higher level of accuracy and consistency, as well as design efficiency, in the capacity predictions of slender stainless steel cross-sections, compared to the effective width methods employed in the current international design standards. Nondoubly symmetric sections in bending, which may be slender, but still benefit from strain hardening, are also discussed. The reliability of the CSM proposal has been confirmed by means of statistical analyses according to EN 1990, demonstrating its suitability for incorporation into future revisions of international design codes for stainless steel structures.

\section{Introduction}

Stainless steel is becoming an increasingly attractive choice as a construction material, rather than simply a decorative material, in a range of engineering applications, owing principally to its favourable mechanical properties, good ductility and excellent corrosion and fire resistance. Given the high initial material price of stainless steels, structural design efficiency is of primary concern. For the design of stainless steel plated sections (e.g., square and rectangular hollow sections (SHS and RHS), I-sections, channel sections, angle sections and T-sections) susceptible to local buckling, although a number of design standards exist, the provisions were generally developed in line with the corresponding carbon steel design guidelines, which are based on the idealised elastic, perfectly-plastic material model without accounting for strain hardening, and the traditional cross-section classification and effective width concepts without considering element interaction. Hence, current stainless steel design standards generally ignore these two beneficial effects - strain hardening and element 
interaction - and have, as a result, been shown to often result in unduly conservative and scattered predictions of cross-section resistances under compression [1-4], bending [3,5-8] and combined loading [9-12].

To address this shortcoming, a deformation-based design approach called the continuous strength method (CSM) has been proposed [13-16]. The CSM replaces the concept of crosssection classification, which is defined on the basis of the most slender constituent plate element of the cross-section, with a non-dimensional measure of cross-section deformation capacity, which is presented as a function of the full cross-section slenderness that accounts for the beneficial effect of element interaction within the cross-section. An elastic, linear hardening material model is also adopted, representing better the actual material behaviour of stainless steels, compared to the elastic, perfectly-plastic material model used in current design standards. The CSM [13-15] has previously been developed for the design of nonslender stainless steel plated sections, and shown to yield substantially improved predictions of capacity over the current design standards, due to the consideration of strain hardening and element interaction, while its application to slender plated sections is extended and described herein.

The paper begins with a brief review and comparative analysis of the current design methods for slender stainless steel cross-sections failing by local buckling, including the European codes EN 1993-1-4 [17] and EN 1993-1-5 [18], American specification SEI/ASCE-8 [19], Australian/New Zealand standard AS/NZS 4673 [20], AISC design guide 27 [21] and direct strength method (DSM) [6,22-25]. The continuous strength method (CSM), originally developed to account for strain hardening in the design of non-slender stainless steel plated sections, is firstly described, and then extended to cover the design of slender cross-sections, 
underpinned by experimental results collected from the literature. A numerical modelling programme is also performed to generate further structural performance data. The present numerical studies focus primarily on tubular SHS and RHS, though a wider study by the authors also includes other open section profiles, such as I-, T-, channel and angle sections. Finally, the combined experimental and numerical data are employed to assess the accuracy and reliability of the proposed CSM for slender stainless steel plated sections.

\section{Current design methods for slender stainless steel cross-sections}

\subsection{Codified design methods}

The codified treatment of local buckling in slender stainless steel cross-sections, as given in the current European codes EN 1993-1-4 [17] and EN 1993-1-5 [18], American specification SEI/ASCE-8 [19], Australian/New Zealand standard AS/NZS 4673 [20] and AISC design guide 27 [21], is based on the traditional effective width concept, as adopted in the corresponding carbon steel design standards. The effective width methods treat the crosssection as an assemblage of isolated plate elements without considering element interaction, and account for loss of effectiveness due to local buckling through a reduction in plate element width. The level of the susceptibility of a plate element to local bucking and thus the reduction in plate width and resistance are dependent on its plate element slenderness $\bar{\lambda}_{l}$, as

defined in Eq. (1), where $\bar{b}$ is the flat width of the plate element, $t$ is the plate thickness, $\varepsilon=\sqrt{\left(235 / f_{y}\right)(E / 210000)}$ is a coefficient related to material properties, in which $f_{y}$ is the material yield stress, taken as the $0.2 \%$ proof stress $\sigma_{0.2}$ for stainless steels, $E$ is the Young's modulus, and $k_{\sigma}$ is the plate buckling coefficient, depending on the edge support conditions and the stress ratio across the plate width. Note that the definition of flat width $\bar{b}$ varies between the design codes and the appropriate width has been used for the calculations and comparisons presented. 


$$
\bar{\lambda}_{l}=\frac{\bar{b} / t}{28.4 \varepsilon \sqrt{k_{\sigma}}}
$$

The reduction factor $\rho$ in plate element width due to local buckling is a function of the plate element slenderness $\bar{\lambda}_{l}$. The American specification SEI/ASCE-8 [19] and Australian/New Zealand standard AS/NZS 4673 [20] adopt the same reduction factor $\left(\rho_{A S C E}=\rho_{A S / N Z S}\right)$, as shown in Eq. (2) for both internal (stiffened) and outstand (unstiffened) plate elements. The reduction factors used in the European code EN 1993-1-4 [17] and AISC design guide 27 [21] are based on the findings of Gardner and Theofanous [26], as given by Eq. (3) and Eq. (4) for internal $\left(\rho_{E C 3-1-4-I}=\rho_{A I S C-I}\right)$ and outstand $\left(\rho_{E C 3-1-4-O}=\rho_{A I S C-O}\right)$ plate elements, respectively. The European code EN 1993-1-5 [18] for plated carbon steel structural elements considers the effect of stress gradient on the local buckling behaviour of internal plate elements, with the reduction factor shown in Eq. (5), where $\psi$ is the end stress ratio of an internal plate element, but employs the same reduction factor for outstand plate elements as those in EN 1993-1-4 [17] and AISC [21], as given by Eq. (6).

$$
\begin{gathered}
\rho_{A S C E}=\rho_{A S / N Z S}=\left(\frac{1}{\bar{\lambda}_{l}}-\frac{0.22}{\bar{\lambda}_{l}^{2}}\right) \leq 1 \\
\rho_{E C 3-1-4-I}=\rho_{A I S C-I}=\left(\frac{0.772}{\bar{\lambda}_{l}}-\frac{0.079}{\bar{\lambda}_{l}^{2}}\right) \leq 1 \\
\rho_{E C 3-1-4-O}=\rho_{A I S C-O}=\left(\frac{1}{\bar{\lambda}_{l}}-\frac{0.188}{\bar{\lambda}_{l}^{2}}\right) \leq 1 \\
\rho_{E C 3-1-5-I}=\left(\frac{1}{\bar{\lambda}_{l}}-\frac{0.055(3+\psi)}{\bar{\lambda}_{l}^{2}}\right) \leq 1 \\
\rho_{E C 3-1-5-O}=\left(\frac{1}{\bar{\lambda}_{l}}-\frac{0.188}{\bar{\lambda}_{l}^{2}}\right) \leq 1
\end{gathered}
$$


On the basis of the effective width of each constituent plate element, the effective crosssection properties, including the effective section area $A_{\text {eff }}$ and modulus $W_{\text {eff, }}$ can be determined. The effective cross-section resistances under pure compression $\left(N_{\text {eff }}\right)$ and bending $\left(M_{\text {eff }}\right)$ are then calculated as the products of the yield stress $f_{y}$ and the effective section area $A_{\text {eff }}$ and modulus $W_{\text {eff, }}$, respectively. For slender cross-sections under combined loading, failure is determined based on a linear summation of the utilization ratios under each component of loading, with a limit of unity. The design expression is given by Eq. (7), in which $N_{E d}$ is the applied axial load, $M_{E d, y}$ and $M_{E d, z}$ are the applied bending moments about the two principal axes, $N_{\text {eff, }} M_{\text {eff, } y}$ and $M_{\text {eff, } z}$ are the corresponding design effective crosssection compression and bending resistances.

$$
\frac{N_{E d}}{N_{e f f}}+\frac{M_{E d, y}}{M_{e f f, y}}+\frac{M_{E d, z}}{M_{e f f, z}} \leq 1
$$

Following comparisons with test and finite element (FE) results, it has been generally found in previous research [27] that the effective width methods result in rather scattered crosssection resistance predictions, especially for sections where the slenderness of the constituent plate elements varies significantly, e.g., RHS with large aspect ratios, owing to the failure to account for the beneficial effect of element interaction in the design. Moreover, application of the effective width method is often cumbersome, due to a shift of neutral axis.

\subsection{The direct strength method (DSM)}

The direct strength method (DSM) was developed by Schafer and Peköz [22,23] to overcome the cumbersome nature of the effective width method when applied to slender cold-formed carbon steel cross-sections of complex geometries or under stress gradients, and to consider the beneficial effect of element interaction in the determination of cross-section resistances. The DSM directly relates the strength of a cross-section to its overall cross-section 
slenderness $\bar{\lambda}_{p}=\sqrt{f_{y} / f_{c r}}$, in which $f_{c r}$ is the elastic buckling stress of the full cross-section under the applied loading conditions, and may be determined using the finite strip software CUFSM [28]. In contrast, the effective width method treats the cross-section as an assemblage of isolated plate elements and calculates the effective width and strength of each plate element based on the individual plate slenderness $\bar{\lambda}_{l}$ without considering the beneficial effect of element interaction. The DSM design resistance formulae are given by Eqs (8) and (9) for cross-sections failing by local buckling in compression $\left(N_{n l}\right)$ and bending $\left(M_{n l}\right)$, respectively, in which $N_{y}$ is the cross-section yield load, equal to the gross cross-section area $A$ multiplied by yield stress $f_{y}$ and $M_{e l}$ is the elastic moment capacity, defined as the product of the cross-section elastic section modulus $W_{e l}$ and yield stress $f_{y}$. Following successful application to cold-formed carbon steel sections, proposals to extend the DSM to structural stainless steel sections of austenitic [24,25], duplex [6] and ferritic [24,25] grades have been set out. Although the DSM approach is currently included in the North American specification for cold-formed carbon steel structures AISI-S100-12 [29], it has not yet been incorporated into stainless steel design standards.

$$
\begin{array}{cc}
\frac{N_{n l}}{N_{y}}=\left\{\begin{array}{cc}
1 & \bar{\lambda}_{p} \leq 0.776 \\
\left(1-\frac{0.15}{\bar{\lambda}_{p}^{0.8}}\right) \frac{1}{\bar{\lambda}_{p}^{0.8}} & \bar{\lambda}_{p}>0.776
\end{array}\right. \\
\frac{M_{n l}}{M_{y}}=\left\{\begin{array}{cc}
1 & \bar{\lambda}_{p} \leq 0.776 \\
\left(1-\frac{0.15}{\bar{\lambda}_{p}^{0.8}}\right) \frac{1}{\bar{\lambda}_{p}^{0.8}} & \bar{\lambda}_{p}>0.776
\end{array}\right.
\end{array}
$$

\section{The continuous strength method (CSM)}

\subsection{Introduction}

The continuous strength method (CSM) [13-16] is a deformation-based design approach, originally developed to allow for a rational exploitation of strain hardening in the design of 
stocky (i.e. non-slender Class 1, 2 and 3) stainless steel cross-sections. It was shown to yield a high level of accuracy and consistency in the resistance predictions of non-slender stainless steel cross-sections under various loading conditions, including pure compression $[4,9-12,14]$, pure bending $[6,8,9-12,14]$ and combined loading [9-12]. In the following sub-section, a brief summary of the CSM for non-slender stainless steel sections is firstly described; extension of the method to slender (Class 4) cross-sections is in Section 3.3.

\subsection{The CSM for non-slender cross-sections}

The main characteristics of the CSM for non-slender sections lie in the employment of a 'base curve' to determine the maximum strain that a cross-section can attain prior to failure by local buckling, and the adoption of an elastic, linear hardening material model to enable design stresses greater than the yield stress. The base curve, derived on the basis of a regression fit to compression and bending test data for a range of metallic materials, including austenitic, duplex and ferritic stainless steels, carbon steel, high strength steel and aluminium, defines the relationship between the deformation capacity, expressed in terms of the strain ratio $\left(\varepsilon_{c s m} / \varepsilon_{y}\right)$, and the full cross-section slenderness $\bar{\lambda}_{p}$, as given by Eq. (10), where $\varepsilon_{c s m}$ is the maximum attainable strain and $\varepsilon_{y}$ is the yield strain equal to $f_{y} / E$. Two limits are applied to the strain ratio $\left(\varepsilon_{c s m} / \varepsilon_{y}\right)$ given by Eq. (10): the first limit of 15 is to prevent excessive strains and also corresponds to the material ductility requirement given in EN 1993-1-4 [17], while the second limit, which is related to the adopted elastic, linear hardening material model, is to avoid over-prediction of the material strength. Similarly to the direct strength method (DSM), the continuous strength method (CSM) also uses the full cross-

section slenderness $\bar{\lambda}_{p}$ rather than the individual plate slenderness $\bar{\lambda}_{l}$, and thus takes into account the beneficial effect of element interaction. Note that the base curve, defined by Eq. 
(10), applies to non-slender cross-sections with $\bar{\lambda}_{p}$ less than or equal to 0.68 , at which point the strain ratio $\varepsilon_{c s m} / \varepsilon_{y}$ is equal to unity.

$$
\frac{\varepsilon_{c s m}}{\varepsilon_{y}}=\frac{0.25}{\bar{\lambda}_{p}^{3.6}} \text { but } \leq \min \left(15, \frac{C_{1} \varepsilon_{u}}{\varepsilon_{y}}\right), \quad \text { for } \bar{\lambda}_{p} \leq 0.68
$$

The CSM elastic, linear hardening material model, which features four material coefficients $\left(C_{1}, C_{2}, C_{3}\right.$ and $\left.C_{4}\right)$, is illustrated in Fig. 1, with the strain hardening slope $E_{s h}$ calculated from Eq. (11). Values of the coefficients for each metallic material were calibrated based on the material tensile coupon test data by means of least squares regression, and are summarised in Table 1 [16]. The CSM material model parameter $C_{1}$ is used to define a cut-off strain (see Eq. (10)) to ensure that the material strength is not over-predicted from the adopted linear hardening material model. The CSM material coefficient $C_{2}$ is employed in Eq. (11) to define the strain hardening slope $E_{s h}$, while the parameter $\varepsilon_{u}=C_{3}\left(1-f_{y} / f_{u}\right)+C_{4}$ is the predicted strain corresponding to the material ultimate strength $f_{u}$.

$$
E_{s h}=\frac{f_{u}-f_{y}}{C_{2} \varepsilon_{u}-\varepsilon_{y}}
$$

Upon determination of the maximum attainable strain $\varepsilon_{c s m}$ and the strain hardening modulus $E_{s h}$, the CSM design stress $f_{c s m}$ can be calculated from Eq. (12), which is then employed directly to obtain the cross-section compression resistance $N_{c s m, R d}$, as given by Eq. (13), where $\gamma_{M 0}$ is a partial factor for cross-section resistance, with a recommended value of 1.1 for stainless steel. Based on the assumption of a linearly-varying through-depth strain distribution and the bi-linear CSM material model, the CSM bending resistance for nonslender cross-sections $M_{c s m, R d}$ can be determined from the design formula given by Eq. (14), where $W_{e l}$ and $W_{p l}$ are the elastic and plastic section moduli, respectively, and $\alpha$ is the CSM 
bending coefficient, related to cross-section shape and axis of bending: for SHS and RHS bending about either axis and for I-sections under major axis bending, $\alpha$ is equal to 2.0, while for I-sections in minor axis bending, $\alpha=1.2$ [14,15]. For mono-symmetric sections (e.g., channel sections and T-sections) and asymmetric sections (e.g., angle sections), the corresponding values of the $\alpha$ coefficient have been recently derived by Zhao and Gardner [30].

$$
\begin{gathered}
f_{c s m}=f_{y}+E_{s h}\left(\varepsilon_{c s m}-\varepsilon_{y}\right) \\
N_{c s m, R d}=\frac{A f_{c s m}}{\gamma_{M 0}} \\
M_{c s m, R d}=\frac{W_{p l} f_{y}}{\gamma_{M 0}}\left[1+\frac{E_{s h}}{E} \frac{W_{e l}}{W_{p l}}\left(\frac{\varepsilon_{c s m}}{\varepsilon_{y}}-1\right)-\left(1-\frac{W_{e l}}{W_{p l}}\right) /\left(\frac{\varepsilon_{c s m}}{\varepsilon_{y}}\right)^{\alpha}\right]
\end{gathered}
$$

The scope of the CSM was extended from isolated loading cases (i.e. pure compression or pure bending) to combined loading cases (i.e. combined compression and bending) by Liew and Gardner [15] and Zhao et al. [10,11]. The proposals utilise the CSM compression and bending resistances as the end points, with efficient cross-section interaction curves between these points.

Following comprehensive comparisons with the test and FE results, it was found that the CSM generally yields a much higher level of accuracy and consistency in the resistance predictions of non-slender stainless steel cross-sections subjected to various loading conditions, including pure compression [4,9-12,14], pure bending [6,8,9-12,14] and combined compression and bending [9-12], owing principally to the consideration of strain hardening. 


\subsection{Extension of the CSM to slender cross-sections}

Upon successful application to non-slender stainless steel cross-sections, the CSM is now extended to cover the design of slender cross-sections, in which local buckling occurs prior to the attainment of the $0.2 \%$ proof stress, and no significant benefit arises from strain hardening. The CSM generally features two key components - a base curve defining the maximum strain that a cross-section can achieve prior to failure by local buckling, and an elastic, linear hardening material model, which offers a simplified representation of the nonlinear stressstrain characteristics of stainless steels. As described previously, the adopted CSM material model was calibrated based on the analysis of material tensile coupon test data, and is thus independent of cross-section slenderness. Therefore, the key step towards extending the CSM to the design of slender cross-sections lies in the development of a second base curve for slender sections with slenderness $\bar{\lambda}_{p}$ greater than 0.68 .

The CSM base curve was derived for non-slender cross-sections through a regression fit to the test data, with the experimental local buckling limiting strain $\varepsilon_{l b}$ taken as the maximum attainable strain at the ultimate load, e.g., $\varepsilon_{l b}$ is equal to the ratio of the end shortening $\delta_{u}$ at failure to the initial specimen length $L$ for stub columns. However, for slender cross-sections that fail by local buckling before yielding, the observed experimental deformation response is strongly influenced by elastic buckling (accompanied by a drop in axial stiffness and hence deviation from the elastic material behaviour) and post-buckling, and thus the base curve developed on the basis of the former definition of the experimental local buckling limiting strain would result in over-predictions of failure stress from the adopted CSM material model, which has a linear stress-strain response up to the yield stress. The above issue is illustrated in Fig. 2, where the experimental stress-strain curve, transformed from the load-end shortening curve of a typical slender section (RHS $100 \times 40 \times 2$ ) stub column test [31], is 
plotted together with the CSM elastic, linear strain hardening material model, indicating that the actual failure stress $f_{u, \text { actual }}$ would be greatly over-predicted by the adopted CSM material model, if the local buckling limiting strain is defined as the maximum strain at the failure load for slender cross-sections.

The concept of equivalent local buckling strain [32] is therefore used in the definition of the experimental limiting strain for slender sections, in order to avoid over-predictions of design failure stress. Considering that the CSM adopts a linear stress-strain material model up to the yield stress, the equivalent experimental local buckling limiting strains $\varepsilon_{l b, e}$ for slender section members that fail below the yield strength are determined based on the assumption of a linear load-deformation structural response, as illustrated in Fig. 2; hence $\varepsilon_{l b, e}=N_{u, t e s t} /(A E)$ and $\varepsilon_{l b, e}=M_{u, t e s t} /\left(W_{e l} E\right)$ for slender section stub columns and beams, respectively, where $N_{u, \text { test }}$ is the test ultimate load and $M_{u, t e s t}$ is the test ultimate bending moment. The experimental local buckling strain ratios for stub columns and beams, defined as the ratio of the equivalent local buckling stain to the yield strain $\varepsilon_{y}$, are now therefore simply equal to the corresponding ratios of the test ultimate capacity to the yield capacity, as shown in Eqs (15) and (16), respectively, where $N_{y}=A f_{y}$ is the cross-section yield load and $M_{y}=W_{e l f}$ is the cross-section elastic bending moment capacity. Additionally, with this adopted definition of deformation capacity, unlike in the development of the base curve for non-slender sections [14], no further account needs to be made for the difference between the actual rounded material stress-strain response and the assumed CSM linear elastic material response below the $0.2 \%$ proof stress, and hence $\varepsilon_{c s m} / \varepsilon_{y}=\varepsilon_{l b, e} / \varepsilon_{y}$.

$$
\begin{aligned}
& \frac{\varepsilon_{c s m}}{\varepsilon_{y}}=\frac{\varepsilon_{l b, e}}{\varepsilon_{y}}=\frac{N_{u, t e s t}}{N_{y}} \\
& \frac{\varepsilon_{c s m}}{\varepsilon_{y}}=\frac{\varepsilon_{l b, e}}{\varepsilon_{y}}=\frac{M_{u, t e s t}}{M_{y}}
\end{aligned}
$$


Previous stub column and beam test data have been collected for the development of the second base curve for slender cross-sections with $\bar{\lambda}_{p}>0.68$. In total, 442 experimental results have been gathered from the literature, including 149 for stainless steel $[1,3-8,31,33-$ 42], 13 for carbon steel [43-46], 61 for high strength steel [47-55], and 219 for aluminium [56-65]. For each data point, the equivalent local buckling limiting strain ratio, as determined from Eq. (15) or Eq. (16), is plotted against the cross-section slenderness in Fig. 3. The base curve is defined by a continuous function of the general form given by Eq. (17), which is similar to that used in other strength-based design approaches, such as the DSM and effective width methods. The values of the parameters $\mathrm{A}$ and $\mathrm{B}$ were determined following a regression fit of Eq. (17) to the test data; for compatibility with the CSM base curve for nonslender cross-sections with $\bar{\lambda}_{p} \leq 0.68$, the base curve for slender sections should also pass through the identified cross-section slenderness limit (transition point) between slender and non-slender sections, i.e. $(0.68,1)$. The derived CSM base curve for slender sections, as defined by Eq. (18), is shown in Fig. 3, together with the design curves from the codified effective width methods for comparison purposes. The full base curve, together with the test data on both stocky and slender cross-sections is also shown in Fig. 4. Note that the continuity of position, but not slope is maintained at $\bar{\lambda}_{p}=0.68$.

$$
\begin{gathered}
\frac{\varepsilon_{c s m}}{\varepsilon_{y}}=\left(1-\frac{A}{\bar{\lambda}_{p}^{B}}\right) \frac{1}{\bar{\lambda}_{p}^{B}} \\
\frac{\varepsilon_{c s m}}{\varepsilon_{y}}=\left(1-\frac{0.222}{\bar{\lambda}_{p}^{1.050}}\right) \frac{1}{\bar{\lambda}_{p}^{1.050}}
\end{gathered}
$$


The CSM cross-section compression and bending resistances are then calculated as the corresponding yield (elastic) strengths multiplied by the strain ratio, as shown in Eqs (19) and (20), respectively.

$$
\begin{gathered}
N_{c s m, R d}=\frac{\varepsilon_{c s m}}{\varepsilon_{y}} \frac{A f_{y}}{\gamma_{M 0}} \\
M_{c s m, R d}=\frac{\varepsilon_{c s m}}{\varepsilon_{y}} \frac{W_{e l} f_{y}}{\gamma_{M 0}}
\end{gathered}
$$

For the design of slender cross-sections under combined axial compressive load and bending moment, a linear interaction formula is employed, as given by Eq. (21), where $N_{c s m, R d}$ is the CSM compression resistance, calculated from Eq. (19), while $M_{c s m, y, R d}$ and $M_{c s m, z, R d}$ are the CSM bending moment resistances about the major and minor axes, respectively, determined from Eq. (20).

$$
\frac{N_{E d}}{N_{c s m, R d}}+\frac{M_{E d, y}}{M_{c s m, y, R d}}+\frac{M_{E d, z}}{M_{c s m, z, R d}} \leq 1
$$

For slender non-doubly symmetric sections (e.g., channel, T- and angle sections) in bending, in the case where the neutral axis is closer to the extreme compressive fibre, although the limiting strain in compression is less than the yield strain, the corresponding strains in tension can be significantly larger than the yield strain, resulting in strain hardening. Therefore, slender non-doubly symmetric sections in bending can also benefit from strain hardening. The CSM can take this beneficial strain hardening effect into account in the design. For slender non-doubly symmetric sections in bending (i.e. cross-section slenderness greater than 0.68), the design local buckling strain in compression $\varepsilon_{c s m}$ is determined from Eq. (18), while the design strain in tension $\varepsilon_{c s m, t}$ can be obtained based on the assumption of a linearlyvarying through-depth strain distribution. For $\varepsilon_{c s m, t} \geq \varepsilon_{y}$ (i.e. when yielding occurs on the 
tensile side), the design position of the neutral axis can be approximated as the mid-point between the elastic and plastic neutral axes for practically used non-doubly symmetric sections in structural engineering $[30,66]$. When $\varepsilon_{c s m, t}<\varepsilon_{y}$, the cross-section remains elastic and the elastic neutral axis is therefore employed in the design calculations. The shift in neutral axis resulting from local buckling is not explicitly considered in the CSM, though this effect is inherently present in the bending test and FE data used to formulate and assess the design proposals; the same approach is adopted in the direct strength method (DSM) but not in the design methods of EN 1993-1-4 [17] and EN 1993-1-5 [18], where the shift in neutral axis should be explicitly determined. The corresponding stress distribution is then derived on the basis of the CSM elastic, linear hardening material model. Fig. 5 illustrates the CSM design strain and stress distribution for a slender T-section in major axis bending. The CSM cross-section bending moment resistance is then determined by integration of the stress distribution throughout the cross-section depth. The detailed development of simplified design equations for slender mono-symmetric and asymmetric cross-sections in bending is described by Zhao and Gardner [30].

The accuracy of the proposed CSM for slender stainless steel cross-sections is evaluated through comparisons against the test and FE data in Section 5 of the paper. The experimental data on a range of section types, including SHS and RHS, I-section, channel section and angle section, were collected from the literature, while the FE results, generated in Section 4, focused primarily on tubular SHS and RHS. With regards to loading type, the experimental dataset includes stub column test results for SHS and RHS [1,3,4,31,33-36,38,39,41,42], Isections [35,40,41], channel sections [35] and angle sections [35], and beam tests results for SHS and RHS [5-8,31,37,38,42], while the numerical study considers SHS and RHS under pure compression, pure bending and combined compression and bending. 


\section{Numerical modelling}

The present numerical modelling programme was carried out through the use of the nonlinear finite element analysis package ABAQUS [67]. Numerical simulations were carried out on stainless steel SHS and RHS stub columns subjected to both concentric and eccentric compression, and beams under four-point bending. A detailed description of the development of the FE models and their validation against experimental results were presented by the authors in previous numerical studies $[10,11,31]$ of stainless steel tubular sections under pure compression, pure bending and combined loading, so only the key features of the modelling are reported herein.

Having been used successfully employed in previous studies [10,11,31] concerning the modelling of stainless steel SHS and RHS structural members, the four-noded doubly curved shell element with reduced integration and finite membrane strain, S4R [67], was adopted in the present numerical studies. An element size equal to the cross-section thickness was used in the flat portions of the modelled cross-sections, while a finer mesh of four elements was assigned to the corners to accurately represent the curved geometry. Symmetry was exploited by modelling only half the cross-section and member length of the concentrically-loaded stub column, uniaxial eccentrically-loaded stub column, and four-point bending FE models. For the biaxial eccentrically-loaded stub column FE models, half the member length but the full cross-section was modelled. Suitable symmetry boundary conditions were applied to each axis of symmetry.

The adopted material properties for the present numerical modelling were taken from previous tests on stainless steel SHS and RHS structural members [9,31]. Table 2 reports the employed material properties for each of the three considered stainless steel grades (austenitic, 
duplex and ferritic), including the Young's modulus $E$, the $0.2 \%$ proof stress $\sigma_{0.2}$, the $1.0 \%$ proof stress $\sigma_{1.0}$, the ultimate tensile strength $\sigma_{u}$ and the strain hardening exponents $n, n_{0.2,1.0}^{\prime}$ and $n_{0.2, u}^{\prime}$, as utilized in the two-stage Ramberg-Osgood (R-O) material model [68-71]. Since ABAQUS [67] requires the material properties to be specified in the form of true stress and log plastic strain for the adopted element type, the measured engineering stress-strain curves from the tensile coupon tests $[9,31]$ were firstly represented by the two-stage Ramberg-Osgood material model, and then converted into true stress-strain curves. Measured corner material properties were also assigned to the curved corner portions of the sections, and to the adjacent flat portions extending beyond the corners to a distance equal to two times the cross-section thickness, in accordance with the previous finding [72,73] that both of the aforementioned regions exhibit similar stress-strain characteristics due to approximately the same degree of strength enhancement experienced during the cold-rolling process. The material properties of the flat material were assigned to the remaining regions of the $\mathrm{FE}$ models.

Stainless steel SHS and RHS structural members are generally fabricated by cold-forming, during which the flat metal sheets are firstly cold-rolled into circular tubes and welded closed, and then gradually deformed into the required profiles by means of dies. Two types of residual stresses - through-thickness bending residual stresses arising from non-uniform plastic deformation during cold-forming and membrane residual stresses induced through uneven cooling upon welding, are introduced into the specimens during the fabrication process and therefore exist in the sections in their unloaded state. However, explicit inclusion of residual stresses in the numerical models was deemed unnecessary, principally owing to the negligible influence of the membrane residual stresses on cold-formed stainless steel 
tubular profiles, and the inherent presence of the more dominant through-thickness residual stresses in the measured material properties [74-76].

The end section boundary conditions of the numerical models were arranged as follows: For the concentrically-loaded stub column FE models, all degrees of freedom of the loaded end section were coupled to a concentric reference point, which only allowed longitudinal translation, to simulate fixed end boundary conditions. With regards to the four-point bending FE models, the end cross-section was coupled to a reference point, located at the bottom (tension) flange of the model, where all degrees of freedom were restrained except for the longitudinal translation and rotation about the axis of buckling, in order to replicate simplysupported boundary conditions. In addition, the cross-section of the beam model under the loading point was set as a rigid body, which only allowed rotation about the loading point and vertical deflection. For each eccentrically-loaded stub column FE model, the loaded end section was coupled to an eccentric reference point, allowing longitudinal translation and rotation about the axis of buckling, to model pin-ended boundary conditions; an axial load was applied to the model through the eccentric reference point, resulting in the application of both axial compressive load and bending moment to the numerical model.

Initial local geometric imperfections are introduced into the cold-formed structural members primarily during the fabrication process and can influence the development of local buckling, the failure load and the post-ultimate behaviour. For each type of the numerical model, the initial local geometric imperfection pattern along the member length was taken as the lowest local buckling model shape under the considered loading condition, which was determined by performing a prior elastic eigenvalue buckling analysis $[10,11,31,77-79]$. The initial local imperfection amplitudes were determined by means of the modified Dawson and Walker 
model $[72,80]$, as given by Eq. (22), where $\sigma_{c r, \min }$ is the minimum elastic buckling stress of all the plate elements making up the cross-section. Upon incorporation of the initial local geometric imperfections into the FE models, geometrically and materially nonlinear analyses were carried out, based on the modified Riks method [67], to determine the failure loads, which were then used to assess the accuracy of the proposed CSM for slender stainless steel cross-sections subjected to a range of loading conditions.

$$
\omega_{D \& W}=0.023\left(\frac{\sigma_{0.2}}{\sigma_{c r, \text { min }}}\right) t
$$

With regards to the geometric dimensions of the modelled cross-sections, the outer width was set equal to $100 \mathrm{~mm}$ while the outer depths ranged from $100 \mathrm{~mm}$ to $200 \mathrm{~mm}$, leading to a spectrum of cross-section aspect ratios between 1.0 and 2.0; the internal corner radii were set equal to the cross-section thickness, which varied from $0.5 \mathrm{~mm}$ to $4 \mathrm{~mm}$, resulting in a range

of cross-section slenderness values $\bar{\lambda}_{p}$ between 0.65 and 2.70 . The member length of each concentrically- or eccentrically-loaded stub column FE model was set equal to four times its mean outer dimension, while the length of each four-point bending FE model was set equal to 15 times its mean outer dimension. For the eccentrically-loaded stub column FE models, the employed initial loading eccentricities ranged from $1 \mathrm{~mm}$ to $500 \mathrm{~mm}$, enabling a broad range of loading combinations (i.e. proportions of bending moment to axial load) to be examined. In total, 645 parametric study results were generated, with 215 for each grade, which included 75 for concentrically-loaded stub columns, 70 for four-point bending beams and 70 for eccentrically-loaded stub columns.

\section{Comparisons with test and FE results}

The accuracy of the proposed design approach, as well as the effective width methods given in the current European codes EN 1993-1-4 [17] and EN 1993-1-5 [18], American 
specification SEI/ASCE-8 [19], Australian/New Zealand standard AS/NZS 4673 [20] and AISC design guide 27 [21], for the design of slender stainless steel cross-sections, was evaluated through comparisons of the test and FE strengths with the unfactored (i.e. all partial factors set to unity) predicted strengths, based on the measured or modelled geometries and weighted average (by area) material properties to allow for the higher strengths in the corners. The direct strength method (DSM) [23], though originally developed for the design of slender carbon steel cross-sections, was also assessed herein for slender stainless steel sections. The comparisons are presented in terms of the ratio of test (or FE) to predicted strengths $R_{u} / R_{u, p r e d}$, as shown in Tables 3(a)-3(c) for concentrically-loaded stub columns, beams and eccentrically-loaded stub columns, respectively, in which $R_{u}$ is equal to the test (or FE) failure load $N_{u}$ for the concentrically- and eccentrically-loaded stub columns, and is equal to the test (or FE) failure moment $M_{u}$ for beams, while $R_{u, p r e d}$ is the corresponding predicted resistance from each design method. Note that ratios greater than unity indicate that the test (or FE) data points are safely predicted.

The mean ratios of test (or FE) to CSM predicted strengths, as reported in Tables 3(a)-3(c), are equal to $1.07,1.23$ and 1.17 with coefficients of the variation $(\mathrm{COV})$ of $0.06,0.05$ and 0.06 for slender stainless steel sections subjected to pure compression, pure bending and combined compression and bending, respectively, revealing that the proposed CSM leads to a higher level of design accuracy and consistency than the European code EN 1993-1-4 [17] and AISC design guide 27 [21] in the prediction of slender stainless steel cross-section resistances. The European code EN 1993-1-5 [18], American specification SEI/ASCE-8 [19] and Australian/New Zealand standard AS/NZS 4673 [20] were generally found to yield more accurate mean ratios of test (or FE) to predicted capacities than the CSM, but with a higher degree of scatter, as shown in Tables 3(a)-3(c). In addition, these three design standards led 
to many resistance predictions on the unconservative side, as can be seen from Figs 6 and 7 , where the ratio of test (or FE) capacity to predicted capacity $R_{u} / R_{u, p r e d}$ is plotted against the cross-section slenderness $\bar{\lambda}_{p}$. Moreover, the effective width approaches generally involve more cumbersome calculation in order to obtain the design resistance, while the CSM directly calculates the design resistance as the product of the cross-section yield (elastic) strength and the strain ratio, and is thus very practical. Note that EN 1993-1-4 [17] and the AISC design guide [21] utilise the same reduction factor for plate elements susceptible to local buckling, but with a different definition of the flat width $\bar{b}$ of the plate element, e.g., for SHS and RHS, $\bar{b}=b-3 t$ is used in EN 1993-1-4 [17], while $\bar{b}=b-2 t-2 r_{i}$ is employed in the AISC design guide [21]; this leads to different capacity predictions, as can be seen from Tables 3(a)-3(c). The direct strength method (DSM) [23] was also shown to result in more accurate strength predictions than the CSM proposal, on average, but a significant portion of the strength predictions lie on the unconservative side, as indicted in Fig. 8. The ratios of test (or FE) failure loads to predicted strengths, arranged by stainless steel grade, are presented in Tables 4(a)-4(c), enabling the accuracy of the design methods to be assessed for each material grade. Figs 9-11 present the comparisons between the CSM and the European code EN 1993-1-4 [17] for austenitic, duplex and ferritic stainless steels, respectively.

Comparisons were also made based on the test data only. The mean ratios of test to CSM predicted capacities $R_{u, t e s t} / R_{u, c s m}$, as reported in Tables 5(a) and 5(b), are 1.07 and 1.22 with the same COV of 0.08 for stub columns and beams, respectively, indicating that the CSM leads to more precise and consistent resistance predictions than the European code EN 19931-4 [17]; this can also be seen in Fig. 12, where the $R_{u, \text { test }} / R_{u, \text { pred }}$ ratio against the cross-section slenderness $\bar{\lambda}_{p}$ is depicted. 


\section{Reliability analysis}

In this section, a statistical analysis is carried out to assess the reliability of the proposed continuous strength method for slender stainless steel cross-sections, according to the provisions of EN 1990 [81]. Table 6 summarises the key calculated statistical parameters, calculated based on a total of 794 test and FE data on slender stainless steel cross-sections subjected to compression, bending and combined loading, where $k_{d, n}$ is the design (ultimate limit state) fractile factor, $b$ is the average ratio of test (or FE) to design model resistance based on a least squares fit to all data, $V_{\delta}$ is the $\mathrm{COV}$ of the tests and FE simulations relative to the resistance model, $V_{r}$ is the combined COV incorporating both model and basic variable uncertainties, and $\gamma_{M 0}$ is the partial safety factor for cross-section resistance. In the reliability analyses, the over-strength ratios for material yield strength were taken as 1.3, 1.1 and 1.2, with COVs of $0.060,0.030$ and 0.045 , for the austenitic, duplex and ferritic stainless steels, respectively, while the $\mathrm{COV}$ of the geometric properties was taken as 0.050 for all the stainless steel grades, as recommended by Afshan et al. [82]. As can be seen from Table 6, the resulting partial factor for each stainless steel grade is less than the currently adopted value of 1.1 in EN 1993-1-4 [17], and thus demonstrate that the proposed CSM for slender stainless steel cross-sections satisfies the reliability requirements of EN 1990 [81].

\section{Conclusions}

Current design provisions for slender stainless steel cross-sections, as set out in the European codes EN 1993-1-4 [17] and EN 1993-1-5 [18], American specification SEI/ASCE-8 [19], Australian/New Zealand standard AS/NZS 4673 [20] and AISC design guide 27 [21], are based on the traditional effective width methods. Comparisons of collected test data from the literature and FE results generated herein with the capacity predictions from these codes generally show a fairly high level of scatter, due mainly to the neglect of the beneficial effect 
of element interaction within the cross-section, and often require cumbersome calculations. To address these shortcomings, an improved design approach has been proposed through extension of the deformation-based continuous strength method (CSM) to cover the design of slender stainless steel cross-sections. The CSM proposal considers the beneficial effect of element interaction within the cross-section, and directly calculates the design strength as the product of the cross-section yield (elastic) strength and the strain ratio, which was shown to yield a high level of design accuracy and consistency, as well as design efficiency, in the prediction of the resistances of slender stainless steel sections. The reliability of the proposal was demonstrated by means of statistical analyses according to EN 1990 [81]. It is therefore recommended that the proposed approach for slender stainless steel cross-sections be considered for incorporation into future revisions of stainless steel structural design standards.

\section{References}

[1] Gardner L, Nethercot DA. Experiments on stainless steel hollow sections - Part 1: Material and cross-sectional behaviour. Journal of Constructional Steel Research, 2004;60(9):1291-318.

[2] Theofanous M, Gardner L. Testing and numerical modelling of lean duplex stainless steel hollow section columns. Engineering Structures, 2009;31(12):3047-58.

[3] Afshan S, Gardner L. Experimental study of cold-formed ferritic stainless steel hollow sections. Journal of Structural Engineering (ASCE), 2013;139(5):717-28.

[4] Shu G, Zheng B, Shen X. Experimental and theoretical study on the behaviour of coldformed stainless steel stub columns. International Journal of Steel Structures, 2013;13(1)14153. 
[5] Gardner L, Nethercot DA. Experiments on stainless steel hollow sections - Part 2: Member behaviour of columns and beams. Journal of Constructional Steel Research, 2004;60(9):1319-32.

[6] Huang Y, Young B. Experimental and numerical investigation of cold-formed lean duplex stainless steel flexural members. Thin-Walled Structures, 2013;73(19):216-28.

[7] Theofanous M, Saliba N, Zhao O, Gardner, L. Ultimate response of stainless steel continuous beams. Thin-Walled Structures, 2014;83:115-27.

[8] Arrayago I, Real E. Experimental study on ferritic stainless steel simply supported and continuous beams. Journal of Constructional Steel Research, 2016;119:50-62.

[9] Zhao O, Rossi B, Gardner L, Young, B. Behaviour of structural stainless steel crosssections under combined loading - Part I: Experimental study. Engineering Structures, 2015;89:236-46.

[10] Zhao O, Rossi B, Gardner L, Young B. Behaviour of structural stainless steel crosssections under combined loading - Part II: Numerical modelling and design approach. Engineering Structures, 2015;89:247-59.

[11] Zhao O, Rossi B, Gardner L, Young B. Experimental and numerical studies of ferritic stainless steel tubular cross-sections under combined compression and bending. Journal of Structural Engineering (ASCE), 2016;142(2):04015110.

[12] Arrayago I, Real E. Experimental study on ferritic stainless steel RHS and SHS crosssectional resistance under combined loading. Structures, 2015;4:69-79. 
[13] Ashraf M, Gardner L, Nethercot DA. Structural stainless steel design: resistance based on deformation capacity. Journal of Structural Engineering (ASCE), 2008;134(3):402-11.

[14] Afshan S, Gardner L. The continuous strength method for structural stainless steel design. Thin-Walled Structures, 2013;68(4):42-49.

[15] Liew A, Gardner L. Ultimate capacity of structural steel cross-sections under compression, bending and combined loading. Structures, 2015;1:2-11.

[16] Buchanan C, Gardner L, Liew A. The continuous strength method for the design of circular hollow sections. Journal of Constructional Steel Research, 2016;118:207-16.

[17] EN 1993-1-4:2006+A1:2015. Eurocode 3: Design of steel structures - Part 1.4: General rules - Supplementary rules for stainless steels, including amendment A1 (2015). Brussels: European Committee for Standardization (CEN); 2015.

[18] EN 1993-1-5. Eurocode 3: Design of steel structures - Part 1.5: Plated structural elements. Brussels: European Committee for Standardization (CEN); 2006.

[19] SEI/ASCE 8-02. Specification for the design of cold-formed stainless steel structural members. Reston: American Society of Civil Engineers (ASCE); 2002.

[20] AS/NZS 4673. Cold-formed stainless steel structures. Sydney: AS/NZS 4673:2001; 2001.

[21] AISC. Design Guide 27: Structural Stainless Steel. American Institute of Steel Construction (AISC); 2013. 
[22] Schafer BW, Peköz T. Direct strength prediction of cold-formed steel members using numerical elastic buckling solutions. Proceedings of the Fourteenth International Speciality Conference on Cold-formed Steel Structures, St. Louis, Missouri, USA; 1998.

[23] Schafer BW. Review: The direct strength method of cold-formed steel member design. Journal of Constructional Steel Research, 2008;64(7):766-78.

[24] Becque J, Lecce M, Rasmussen KJR. The direct strength method for stainless steel compression members. Journal of Constructional Steel Research, 2008;64(11):1231-8.

[25] Rossi B, Rasmussen KJR. Carrying capacity of stainless steel columns in the low slenderness range. Journal of Structural Engineering (ASCE), 2012;139(6):1088-92.

[26] Gardner L, Theofanous M. Discrete and continuous treatment of local buckling in stainless steel elements. Journal of Constructional Steel Research, 2008;64(11):1207-16.

[27] Theofanous M, Gardner L. Effect of element interaction and material nonlinearity on the ultimate capacity of stainless steel cross-sections. Steel and Composite Structures, 2012;12(1):73-92.

[28] Schafer BW, Ádány S. Buckling analysis of cold-formed steel members using CUFSM: conventional and constrained finite strip methods. Proceedings of the Eighteenth International Speciality Conference on Cold-formed Steel Structures, Orlando, USA; 2006.

[29] AISI-S100-12. North American specification for the design of cold-formed steel structural members. Washington, D.C.: American Iron and Steel Institute (AISI); 2012. 
[30] Zhao O, Gardner L. Design of non-doubly symmetric stainless steel sections in bending. Journal of Constructional Steel Research, under review.

[31] Zhao O, Gardner L, Young B. Buckling of ferritic stainless steel members under combined axial compression and bending. Journal of Constructional Steel Research, $2016 ; 117: 35-48$.

[32] Anwar-Us-Saadat M, Ashraf M, Ahmed S. Behaviour and design of stainless steel slender cross-sections subjected to combined loading. Thin-Walled Structures, $2016 ; 104: 225-37$.

[33] Talja A, Salmi P. Design of stainless steel RHS beams, columns and beam-columns. Research note 1619, VTT building technology, Finland; 1995.

[34] Liu Y, Young B. Buckling of stainless steel square hollow section compression members. Journal of Constructional Steel Research, 2003;59(2):165-77.

[35] Kuwamura H. Local buckling of thin-walled stainless steel members. International Journal of Steel Structures, 2003;3(3):191-201.

[36] Young B, Lui WM. Behavior of cold-formed high strength stainless steel sections. Journal of Structural Engineering (ASCE), 2005;131(11):1738-45.

[37] Zhou F, Young B. Tests of cold-formed stainless steel tubular flexural members. ThinWalled Structures, 2005;43(9):1325-37.

[38] Gardner L, Talja A, Baddoo NR. Structural design of high-strength austenitic stainless steel. Thin-Walled Structures, 2006;44(5):517-28. 
[39] Huang Y, Young B. Material properties of cold-formed lean duplex stainless steel sections. Thin-Walled Structures, 2012;54(7):72-81.

[40] Saliba N, Gardner L. Cross-section stability of lean duplex stainless steel welded Isections. Journal of Constructional Steel Research, 2013;80:1-14.

[41] Yuan HX, Wang YQ, Shi YJ, Gardner L. Stub column tests on stainless steel built-up sections. Thin-Walled Structures, 2014;83:103-14.

[42] Bock M, Arrayago I, Real E. Experiments on cold-formed ferritic stainless steel slender sections. Journal of Constructional Steel Research, 2015;109:13-23.

[43] Zhao XL, Hancock GJ. Tests to determine plate slenderness limits for cold-formed rectangular hollow sections of grade C450. Steel Construction, 1991;25(4):2-16.

[44] Sakino K, Nakahara H, Morino S, Nishiyama I. Behavior of centrally loaded concretefilled steel-tube short columns. Journal of Structural Engineering (ASCE), 2004;130(2):1808.

[45] Greiner R, Kettler M, Lechner A, Freytag B, Linder J, Jaspart JP, Boissonnade N, Bortolotti E, Weynand K, Ziller C, Oerder R. SEMI-COMP: Plastic Member Capacity of Semi-Compact Steel Sections-a more Economic Design. RFSR-CT-2004-00044, Final Report, Research Programme of the Research Fund for Coal and Steel-RTD; 2008.

[46] Gardner L, Saari N, Wang F. Comparative experimental study of hot-rolled and coldformed rectangular hollow sections. Thin-Walled Structures, 2010;48(7):495-507. 
[47] Nishino F, Ueda Y, Tall L. Experimental investigation of the buckling of plates with residual stresses. Test methods for compression members, ASTM International; 1967.

[48] Usami T, Fukumoto Y. Welded box compression members. Journal of Structural Engineering, 1984;110(10):2457-70.

[49] Rasmussen KJR, Hancock GJ. Plate slenderness limits for high strength steel sections. Journal of Constructional Steel Research, 1992;23(1):73-96.

[50] Im SW, Ko SK, Chang IH. A study on the characteristics of high tensile strength steel (SM570) plates in compression members. Journal of Korean Society of Steel Construction, $2001 ; 13(3): 223-32$.

[51] Im SW, Kim YS, Chang IH. A study on the characteristics of SM570TMC plates in compression members. Journal of Korean Society of Steel Construction, 2005;17(3):357-63.

[52] Gao L, Sun H, Jin F, Fan H. Load-carrying capacity of high-strength steel box-sections I: Stub columns. Journal of Constructional Steel Research, 2009;65(4):918-24.

[53] Lee CH, Kim DK, Han KH, Kim JH, Lee SE, Ha TH. Compressive strength and residual stress evaluation of stub columns fabricated of high strength steel. Journal of Korean Society of Steel Construction, 2012;24(1):23-34.

[54] Yoo JH, Kim JW, Yang JG, Kang JW, Lee MJ. Local buckling in the stub columns fabricated with HSA800 of high performance steel. International Journal of Steel Structures, 2013;13(3):445-58. 
[55] Shi G, Zhou W, Bai Y, Lin C. Local buckling of 460MPa high strength steel welded section stub columns under axial compression. Journal of Constructional Steel Research, 2014;100:60-70.

[56] Bijlaard PP, Fisher GP. Column strength of H-sections and square tubes in post buckling range of component plates. Technical Note 2994, Washington DC: National Advisory Committee for Aeronautics; 1953.

[57] Langseth M, Hopperstad OS. Local buckling of square thin-walled aluminum extrusions. Thin-Walled Structures, 1997;27(1):117-26.

[58] Moen LA, Hopperstad OS, Langseth M. Rotational capacity of aluminum beams under moment gradient. I: Experiments. Journal of Structural Engineering (ASCE), 1999;125(8):910-20.

[59] Faella C, Mazzolani FM, Piluso V, Rizzano G. Local buckling of aluminum members: testing and classification. Journal of Structural Engineering (ASCE), 2000;126(3):353-60.

[60] Mazzolani FM, Piluso V, Rizzano G. Experimental analysis of aluminum alloy channels subjected to local buckling under uniform compression. Proceedings of XVIII CTA Congress, Venice, Italy; 2001

[61] Mennink, J. Cross-sectional stability of aluminum extrusions: Prediction of the actual local buckling behavior. PhD Thesis; 2002.

[62] Zhu JH, Young B. Tests and design of aluminum alloy compression members. Journal of Structural Engineering (ASCE), 2006;132(7):1096-107. 
[63] Zhu JH, Young B. Experimental investigation of aluminum alloy thin-walled tubular members in combined compression and bending. Journal of Structural Engineering (ASCE), 2006;132(12):1955-66.

[64] Zhu JH, Young B. Design of aluminum alloy flexural members using direct strength method. Journal of Structural Engineering (ASCE), 2009;135(5):558-66.

[65] Mazzolani FM, Piluso V, Rizzano G. Local buckling of aluminum alloy angles under uniform compression. Journal of Structural Engineering (ASCE), 2010;137(2):173-84.

[66] Theofanous M, Liew A, Gardner L. Experimental study of stainless steel angles and channels in bending. Structures, 2015;4:80-90.

[67] Hibbitt, Karlsson \& Sorensen, Inc. ABAQUS. ABAQUS/Standard user's manual volumes I-III and ABAQUS CAE manual. Version 6.12. Pawtucket (USA); 2012.

[68] Ramberg W, Osgood WR. Description of stress-strain curves by three parameters. Technical note 902, Washington DC: National Advisory Committee for Aeronautics; 1943.

[69] Hill HN. Determination of stress-strain relations from offset yield strength values. Technical note 927, Washington DC: National advisory committee for aeronautics; 1944.

[70] Mirambell E, Real E. On the calculation of deflections in structural stainless steel beams: An experimental and numerical investigation. Journal of Constructional Steel Research, 2000;54(1):109-33.

[71] Gardner L, Ashraf M. Structural design for non-linear metallic materials. Engineering Structures, 2006;28(6):926-34. 
[72] Gardner L, Nethercot DA. Numerical modeling of stainless steel structural components A consistent approach. Journal of Structural Engineering (ASCE), 2004;130(10):1586-601.

[73] Cruise RB, Gardner L. Strength enhancements induced during cold forming of stainless steel sections. Journal of Constructional Steel Research, 2008;64(11):1310-6.

[74] Rasmussen KJR, Hancock GJ. Design of cold-formed stainless steel tubular members. I: Columns. Journal of Structural Engineering (ASCE), 1993;119(8):2349-67.

[75] Cruise RB, Gardner L. Residual stress analysis of structural stainless steel sections. Journal of Constructional Steel Research, 2008;64(3):352-66.

[76] Jandera M, Gardner L, Machacek J. Residual stresses in cold-rolled stainless steel hollow sections. Journal of Constructional Steel Research, 2008;64(11):1255-63.

[77] Zhao O, Gardner L, Young B. Structural performance of stainless steel circular hollow sections under combined axial load and bending - Part 2: Parametric studies and design. Thin-Walled Structures, 2016;101:240-8.

[78] Zhao O, Gardner L, Young B. Testing and numerical modelling of austenitic stainless steel CHS beam-columns. Engineering Structures, 2016;111:263-74.

[79] Zhao O, Gardner L, Young B. Behaviour and design of stainless steel SHS and RHS beam-columns. Thin-Walled Structures, 2016;106:330-45.

[80] Dawson RG, Walker AC. Post-buckling of geometrically imperfect plates. Journal of the Structural Division (ASCE), 1972;98(1):75-94. 
[81] EN 1990. Eurocode - basis of structural design. Brussels: European Committee for Standardization (CEN); 2002.

[82] Afshan S, Francis P, Baddoo NR, Gardner L. Reliability analysis of structural stainless steel design provisions. Journal of Constructional Steel Research, 2015;114:293-304. 


\section{List of Tables}

Table 1 Summary of the CSM material model coefficients for each metallic material.

\begin{tabular}{lcccc}
\hline Material & $C_{1}$ & $C_{2}$ & $C_{3}$ & $C_{4}$ \\
\hline Hot-finished carbon steel & $-{ }^{\mathrm{a}}$ & $--^{\mathrm{a}}$ & $-^{\mathrm{a}}$ & $-^{\mathrm{a}}$ \\
Cold-formed carbon steel & 0.40 & 0.45 & 0.60 & 0 \\
High strength steel & 0.40 & 0.45 & 0.60 & 0 \\
Austenitic and duplex stainless steels & 0.10 & 0.16 & 1.00 & 0 \\
Ferritic stainless steel & 0.40 & 0.45 & 0.60 & 0 \\
Aluminium & 0.50 & 0.50 & 0.13 & 0.06 \\
\hline
\end{tabular}

${ }^{a}$ Hot-finished carbon steel material model is under development.

Table 2 Summary of key measured material properties from the tensile flat and corner coupons employed in the FE models.

(a) Flat material properties.

\begin{tabular}{cccccccc}
\hline Material grade & $E$ & $\sigma_{0.2}$ & $\sigma_{1.0}$ & $\sigma_{u}$ & \multicolumn{3}{c}{ R-O exponents } \\
\cline { 6 - 8 } & $(\mathrm{GPa})$ & $(\mathrm{MPa})$ & $(\mathrm{MPa})$ & $(\mathrm{MPa})$ & $n$ & $n_{0.2,1.0}^{\prime}$ & $n_{0.2, u}^{\prime}$ \\
\hline Austenitic & 193 & 343 & 391 & 605 & 6.7 & 2.4 & 3.1 \\
Duplex & 199 & 519 & 578 & 728 & 5.3 & 2.8 & 3.7 \\
Ferritic & 199 & 470 & 485 & 488 & 7.3 & 7.6 & 10.9 \\
\hline
\end{tabular}

(b) Corner material properties.

\begin{tabular}{cccccccc}
\hline Material grade & $E$ & $\sigma_{0.2}$ & $\sigma_{1.0}$ & $\sigma_{u}$ & \multicolumn{3}{c}{ R-O exponents } \\
\cline { 6 - 8 } \cline { 5 - 8 } & $(\mathrm{GPa})$ & $(\mathrm{MPa})$ & $(\mathrm{MPa})$ & $(\mathrm{MPa})$ & $n$ & $n_{0.2,1.0}^{\prime}$ & $n_{0.2, u}^{\prime}$ \\
\hline Austenitic & 193 & 526 & 601 & 687 & 10.8 & 3.0 & 3.5 \\
Duplex & 207 & 831 & 906 & 920 & 8.9 & 6.1 & 4.4 \\
Ferritic & 200 & 579 & - & 648 & 4.0 & - & 7.3 \\
\hline
\end{tabular}

Table 3 Comparisons of test and FE results with predicted strengths for each loading case.

(a) Concentrically-loaded stub columns (pure compression)

\begin{tabular}{cccccccc}
\hline & EN 1993-1-4 & EN 1993-1-5 & AISC & ASCE & AS/NZS & CSM & DSM \\
\hline No. of test data: 127 & \multirow{2}{*}{$R_{u} / R_{u, E C 3-1-4}$} & $R_{u} / R_{u, E C 3-1-5}$ & $R_{u} / R_{u, A I S C}$ & $R_{u} / R_{u, A S C E}$ & $R_{u} / R_{u, A S / N Z S}$ & $R_{u} / R_{u, C S M}$ & $R_{u} / R_{u, D S M}$ \\
No. of FE data: 225 & 1.12 & 1.00 & 1.07 & 0.98 & 0.98 & 1.07 & 0.96 \\
\hline Mean & 0.06 & 0.07 & 0.06 & 0.07 & 0.07 & 0.06 & 0.08 \\
\hline COV & &
\end{tabular}


(b) Beams (pure bending)

\begin{tabular}{cccccccc}
\hline & EN 1993-1-4 & EN 1993-1-5 & AISC & ASCE & AS/NZS & CSM & DSM \\
\hline No. of test data: 22 & $R_{u} / R_{u, E C 3-1-4}$ & $R_{u} / R_{u, E C 3-1-5}$ & $R_{u} / R_{u, A I S C}$ & $R_{u} / R_{u, A S C E}$ & $R_{u} / R_{u, A S / N Z S}$ & $R_{u} / R_{u, C S M}$ & $R_{u} / R_{u, D S M}$ \\
No. of FE data: 210 & 1.30 & 1.14 & 1.24 & 1.10 & 1.10 & 1.23 & 1.11 \\
\hline Mean & 0.04 & 0.08 & 0.04 & 0.11 & 0.11 & 0.05 & 0.07 \\
COV & & &
\end{tabular}

(c) Eccentrically-loaded stub columns (combined compression and bending)

\begin{tabular}{cccccccc}
\hline & EN 1993-1-4 & EN 1993-1-5 & AISC & ASCE & AS/NZS & CSM & DSM \\
\hline $\begin{array}{c}\text { No. of test data: } 0 \\
\text { No. of FE data: } 210\end{array}$ & $R_{u} / R_{u, E C 3-1-4}$ & $R_{u} / R_{u, E C 3-1-5}$ & $R_{u} / R_{u, A I S C}$ & $R_{u} / R_{u, A S C E}$ & $R_{u} / R_{u, A S / N Z S}$ & $R_{u} / R_{u, C S M}$ & $R_{u} / R_{u, D S M}$ \\
\hline Mean & 1.29 & 1.10 & 1.22 & 1.07 & 1.07 & 1.17 & 1.03 \\
COV & 0.05 & 0.09 & 0.05 & 0.09 & 0.09 & 0.06 & 0.10 \\
\hline
\end{tabular}

Table 4 Comparisons of test and FE results with predicted strengths for each stainless steel grade.

(a) Austenitic stainless steel

\begin{tabular}{cccccccc}
\hline & EN 1993-1-4 & EN 1993-1-5 & AISC & ASCE & AS/NZS & CSM & DSM \\
\hline No. of test data: 104 & $R_{u} / R_{u, E C 3-1-4}$ & $R_{u} / R_{u, E C 3-1-5}$ & $R_{u} / R_{u, A I S C}$ & $R_{u} / R_{u, A S C E}$ & $R_{u} / R_{u, A S / N Z S}$ & $R_{u} / R_{u, C S M}$ & $R_{u} / R_{u, D S M}$ \\
No. of FE data: 215 & 1.19 & 1.06 & 1.14 & 1.03 & 1.03 & 1.12 & 1.02 \\
\hline Mean & 0.10 & 0.11 & 0.09 & 0.11 & 0.11 & 0.09 & 0.11 \\
COV & & &
\end{tabular}

(b) Duplex stainless steel

\begin{tabular}{cccccccc}
\hline & EN 1993-1-4 & EN 1993-1-5 & AISC & ASCE & AS/NZS & CSM & DSM \\
\hline No. of test data: 22 & $R_{u} / R_{u, E C 3-1-4}$ & $R_{u} / R_{u, E C 3-1-5}$ & $R_{u} / R_{u, A I S C}$ & $R_{u} / R_{u, A S C E}$ & $R_{u} / R_{u, A S / N Z S}$ & $R_{u} / R_{u, C S M}$ & $R_{u} / R_{u, D S M}$ \\
No. of FE data: 215 & 1.27 & 1.08 & 1.20 & 1.05 & 1.05 & 1.18 & 1.04 \\
\hline Mean & 0.08 & 0.09 & 0.08 & 0.10 & 0.10 & 0.07 & 0.10 \\
\hline
\end{tabular}

(c) Ferritic stainless steel

\begin{tabular}{cccccccc}
\hline & EN 1993-1-4 & EN 1993-1-5 & AISC & ASCE & AS/NZS & CSM & DSM \\
\hline No. of test data: 23 & $R_{u} / R_{u, E C 3-1-4}$ & $R_{u} / R_{u, E C 3-1-5}$ & $R_{u} / R_{u, A I S C}$ & $R_{u} / R_{u, A S C E}$ & $R_{u} / R_{u, A S / N Z S}$ & $R_{u} / R_{u, C S M}$ & $R_{u} / R_{u, D S M}$ \\
No. of FE data: 215 & 1.21 & 1.05 & 1.15 & 1.02 & 1.02 & 1.14 & 1.01 \\
\hline Mean & 0.08 & 0.09 & 0.08 & 0.10 & 0.10 & 0.08 & 0.10 \\
COV & &
\end{tabular}


Table 5 Comparisons of test results with predicted strengths for each loading case.

(a) Concentrically-loaded stub columns (pure compression)

\begin{tabular}{cccccccc}
\hline & EN 1993-1-4 & EN 1993-1-5 & AISC & ASCE & AS/NZS & CSM \\
\hline No. of test data: 127 & $R_{u, \text { test }} / R_{u, E C 3-1-4}$ & $R_{u, \text { test }} / R_{u, E C 3-1-5}$ & $R_{u, \text { test }} / R_{u, \text { AISC }}$ & $R_{u, \text { test }} / R_{u, A S C E}$ & $R_{u, \text { test }} / R_{u, A S / N Z S}$ & $R_{u, \text { test }} / R_{u, \text { CSM }}$ & $R_{u, \text { test }} / R_{u, \text { DSM }}$ \\
\hline Mean & 1.11 & 1.02 & 1.07 & 0.99 & 0.99 & 1.07 & 0.98 \\
COV & 0.08 & 0.09 & 0.07 & 0.09 & 0.09 & 0.08 & 0.09 \\
\hline
\end{tabular}

(b) Beams (pure bending)

\begin{tabular}{cccccccc}
\hline & EN 1993-1-4 & EN 1993-1-5 & AISC & ASCE & AS/NZS & CSM \\
\hline No. of test data: 22 & $R_{u, \text { test }} / R_{u, E C 3-1-4}$ & $R_{u, \text { test }} / R_{u, E C 3-1-5}$ & $R_{u, \text { test }} / R_{u, \text { AISC }}$ & $R_{u, \text { test }} / R_{u, A S C E}$ & $R_{u, \text { test }} / R_{u, A S / N Z S}$ & $R_{u, \text { test }} / R_{u, C S M}$ & $R_{u, \text { test }} / R_{u, \text { DSM }}$ \\
\hline Mean & 1.31 & 1.21 & 1.26 & 1.19 & 1.19 & 1.22 \\
COV & 0.08 & 0.07 & 0.08 & 0.08 & 0.08 & 0.08 & 0.07 \\
\hline
\end{tabular}

Table 6 Reliability analysis results calculated according to EN 1990.

\begin{tabular}{ccccccc}
\hline Grade & No. of test and FE data & $k_{d, n}$ & $b$ & $V_{\delta}$ & $V_{r}$ & $\gamma_{M 0}$ \\
\hline Austenitic & 319 & 3.121 & 1.056 & 0.088 & 0.117 & 1.05 \\
Duplex & 237 & 3.132 & 1.104 & 0.073 & 0.093 & 1.10 \\
Ferritic & 238 & 3.132 & 1.072 & 0.079 & 0.104 & 1.08 \\
\hline
\end{tabular}




\section{List of Figures}

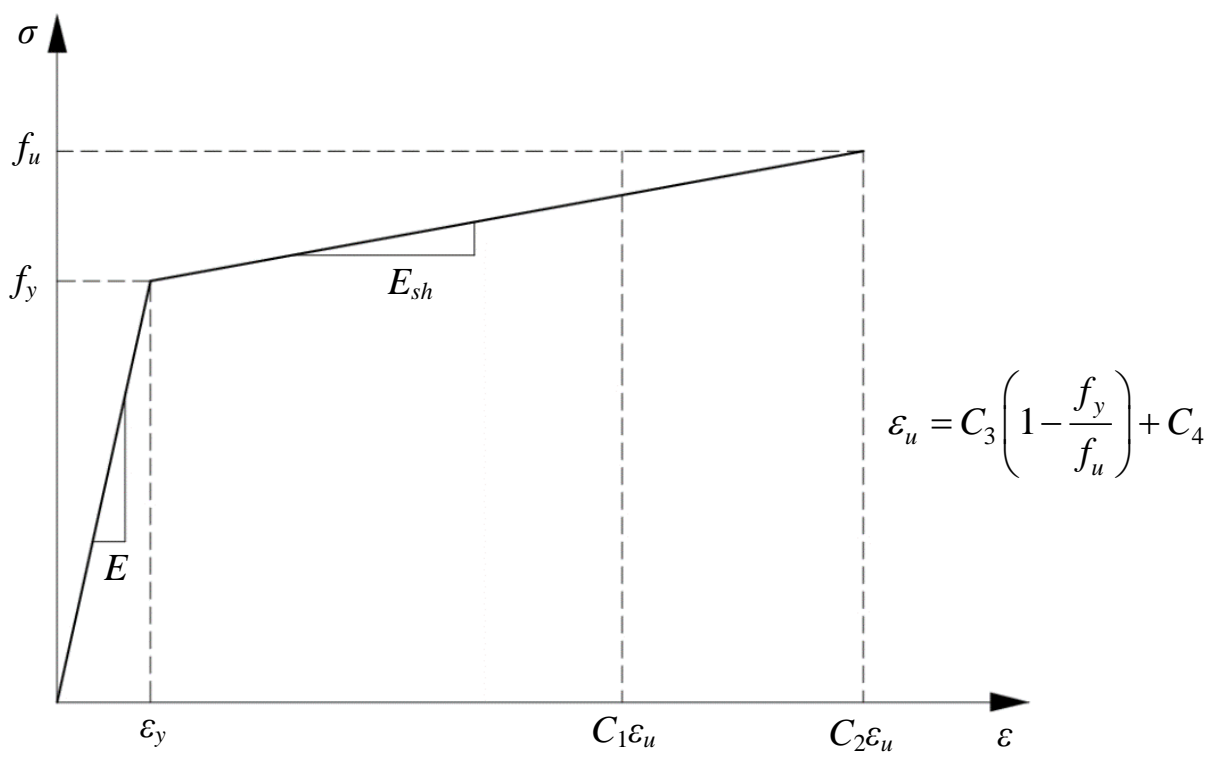

Fig. 1. CSM elastic, linear hardening material model.

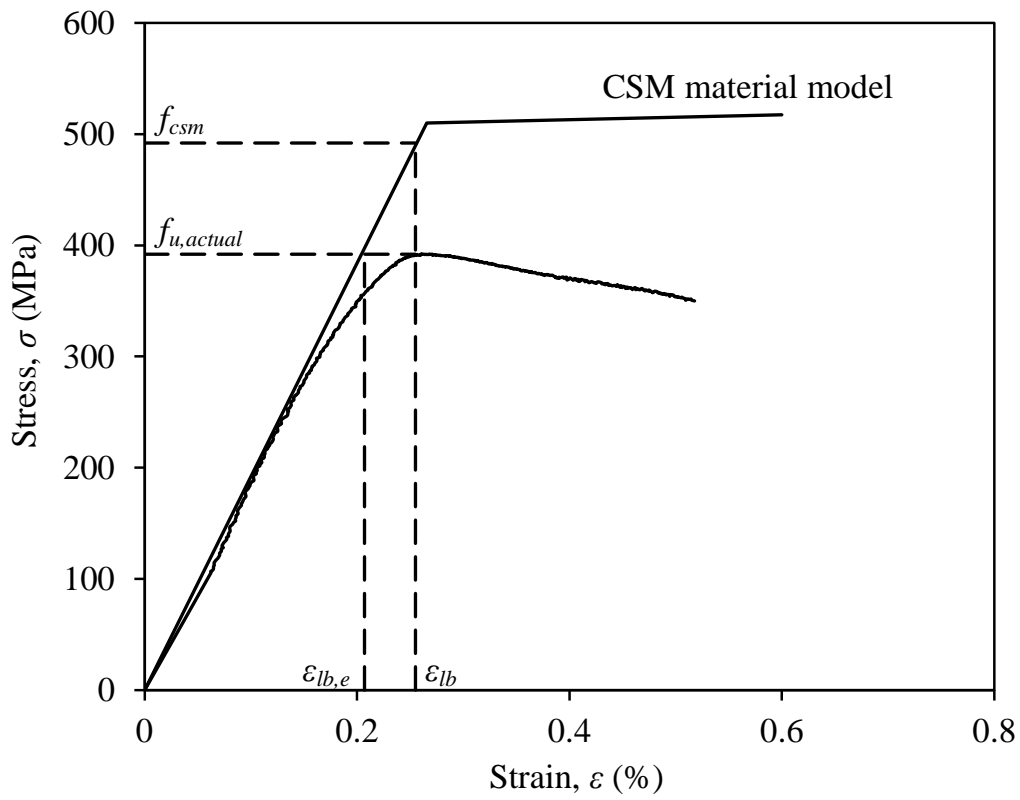

Fig. 2. Comparison of stress-strain curve from a slender section stub column test [31] with CSM material model. 


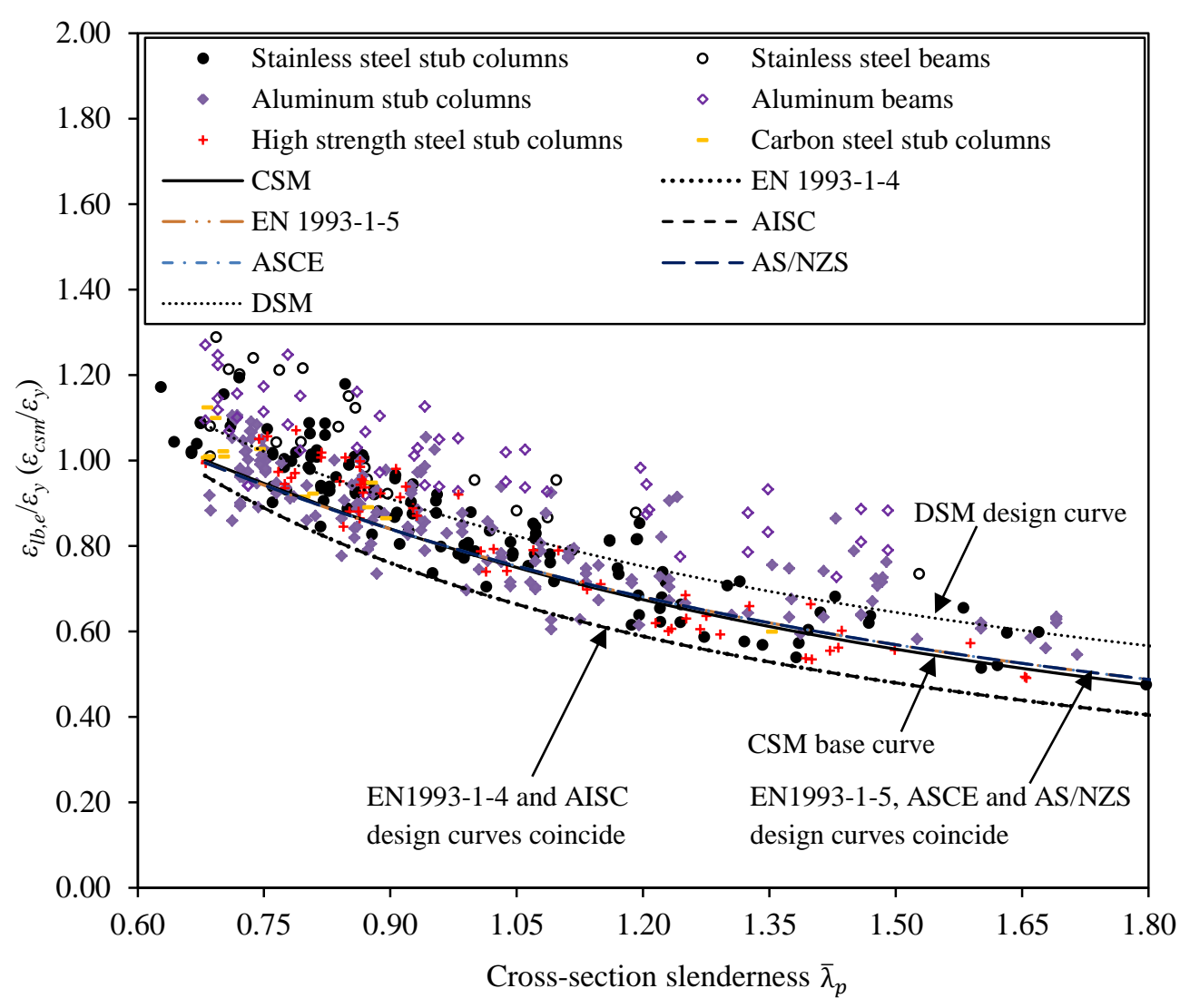

Fig. 3. Experimental equivalent local buckling strain ratio plotted against cross-section slenderness.

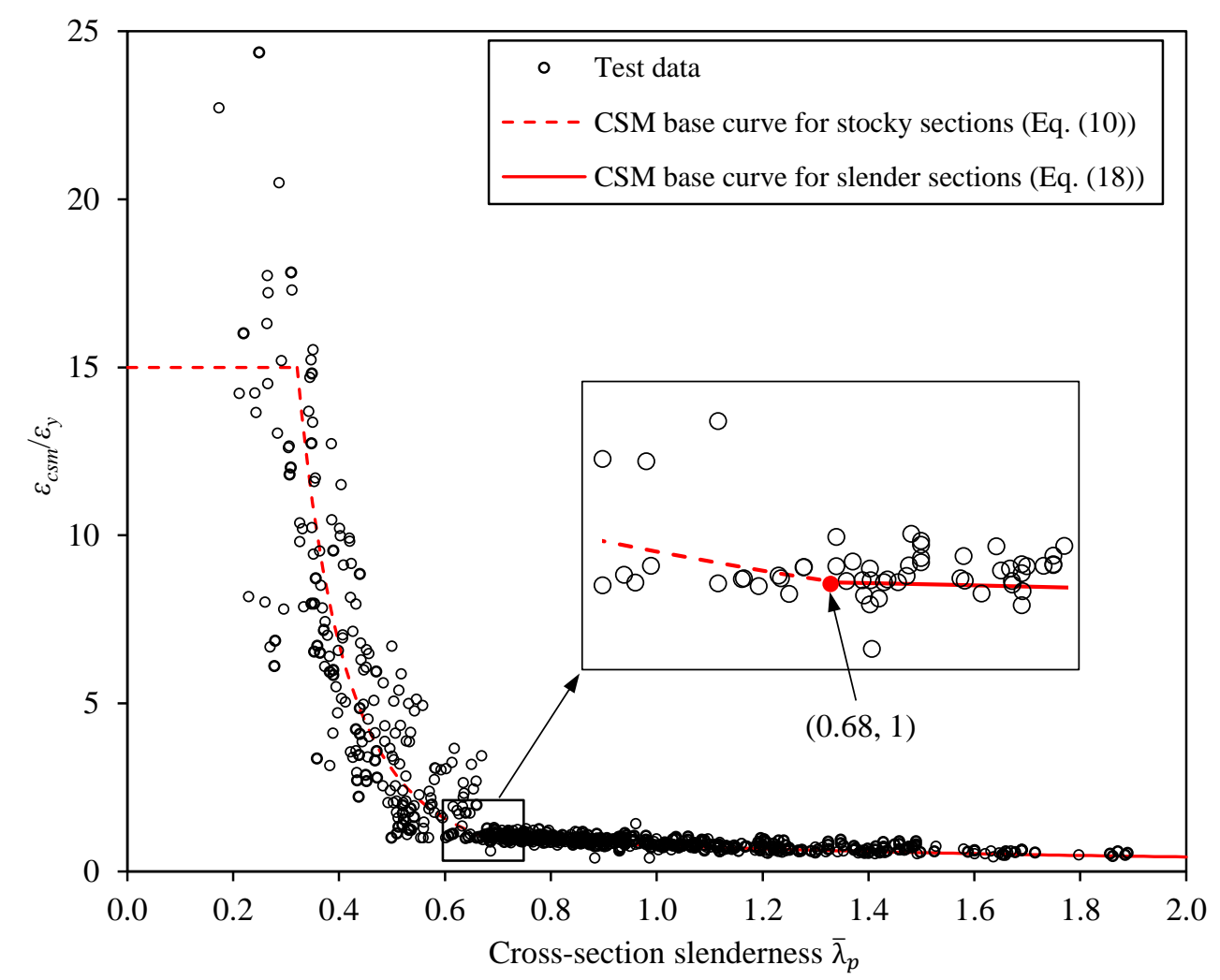

Fig. 4. Full CSM base curve with test data on both stocky and slender cross-sections. 


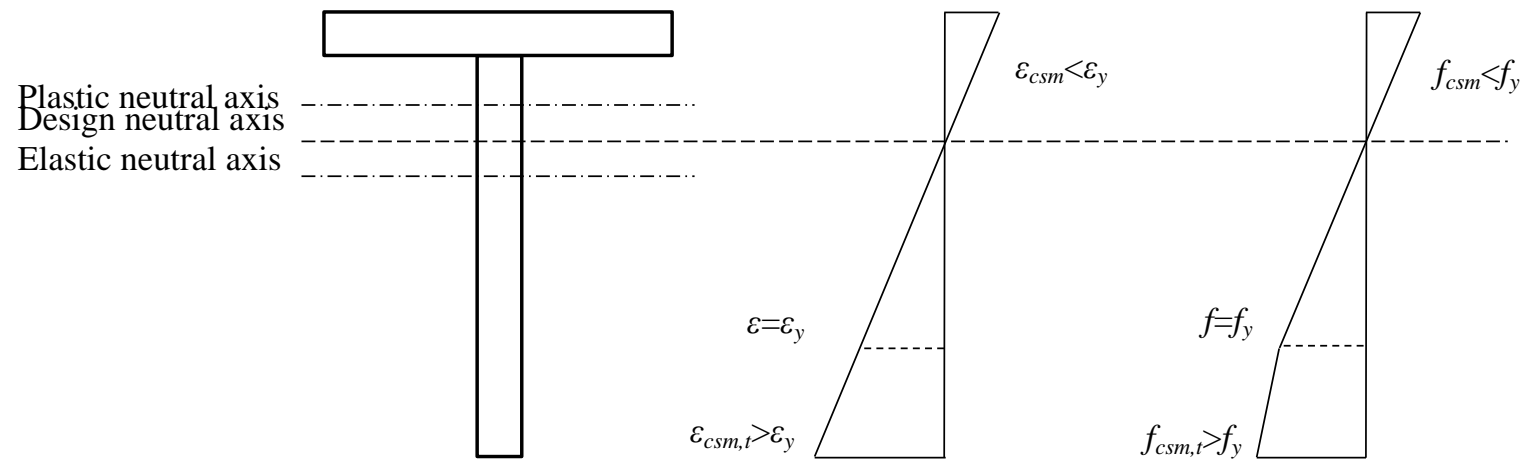

Fig. 5. Illustration of CSM strain and stress distribution for a slender T-section in bending.

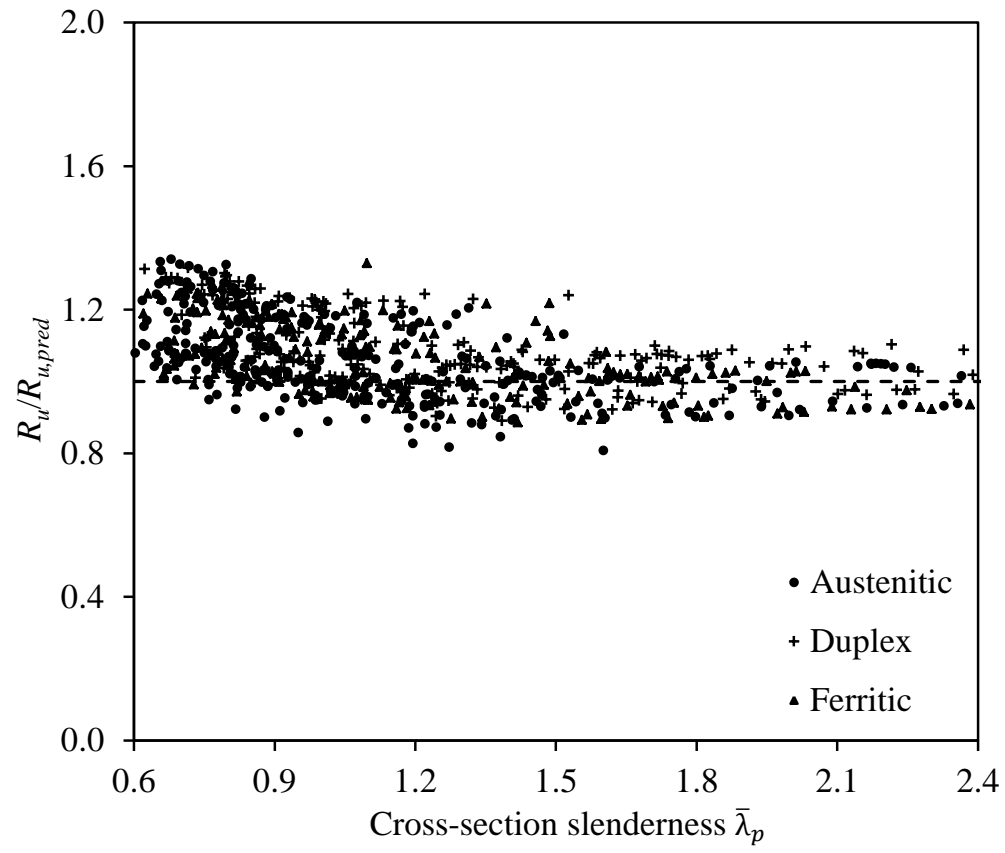

Fig. 6. Comparison of stainless steel test and FE results with EN 1993-1-5 strength predictions. 


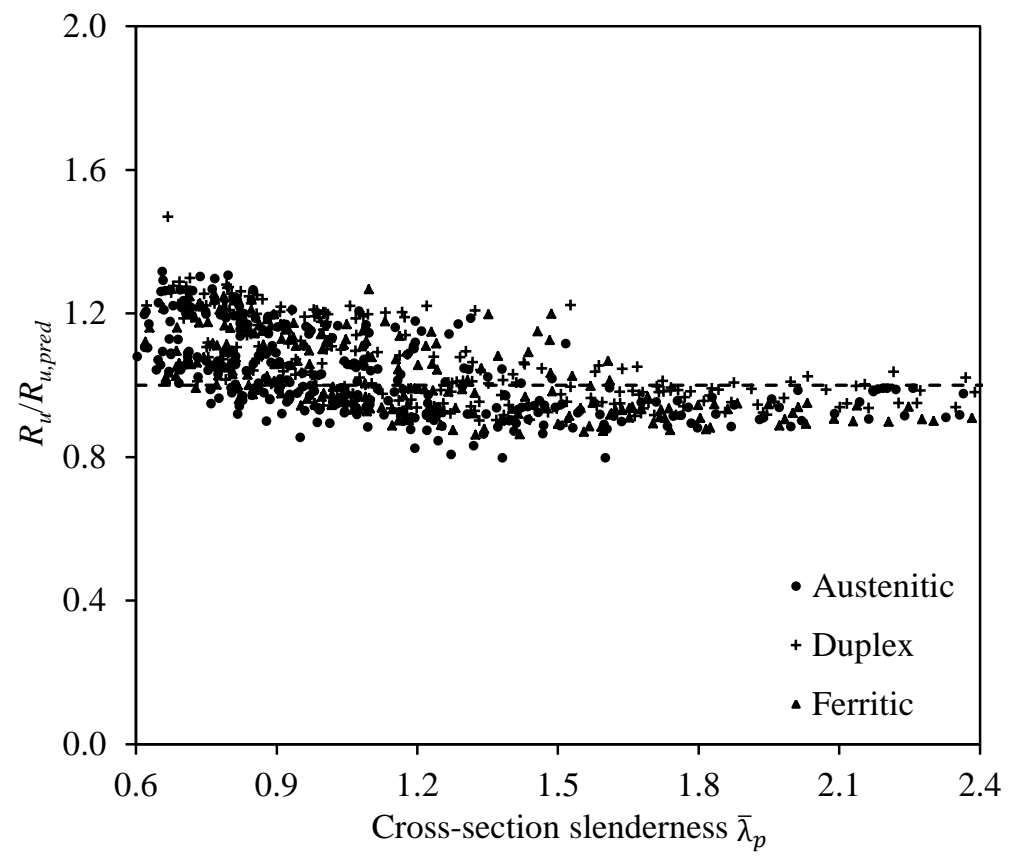

Fig. 7. Comparison of stainless steel test and FE results with SEI/ASCE (or AS/NZS 4673) strength predictions.

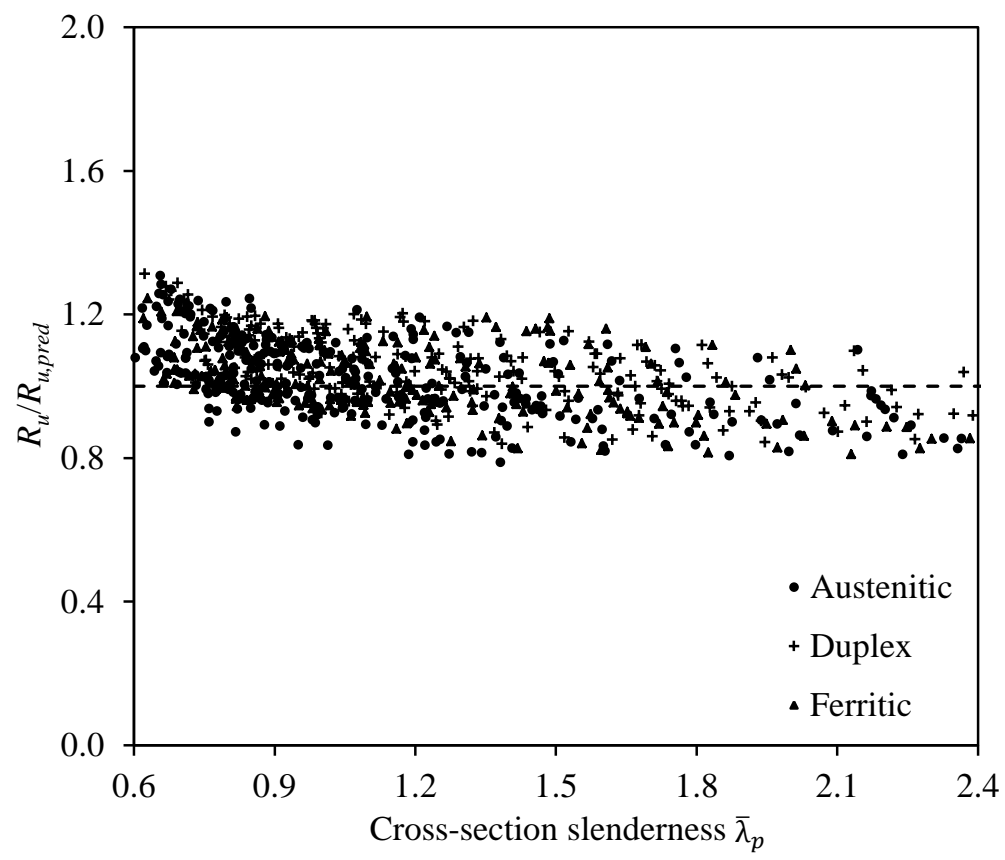

Fig. 8. Comparison of stainless steel test and FE results with DSM strength predictions. 


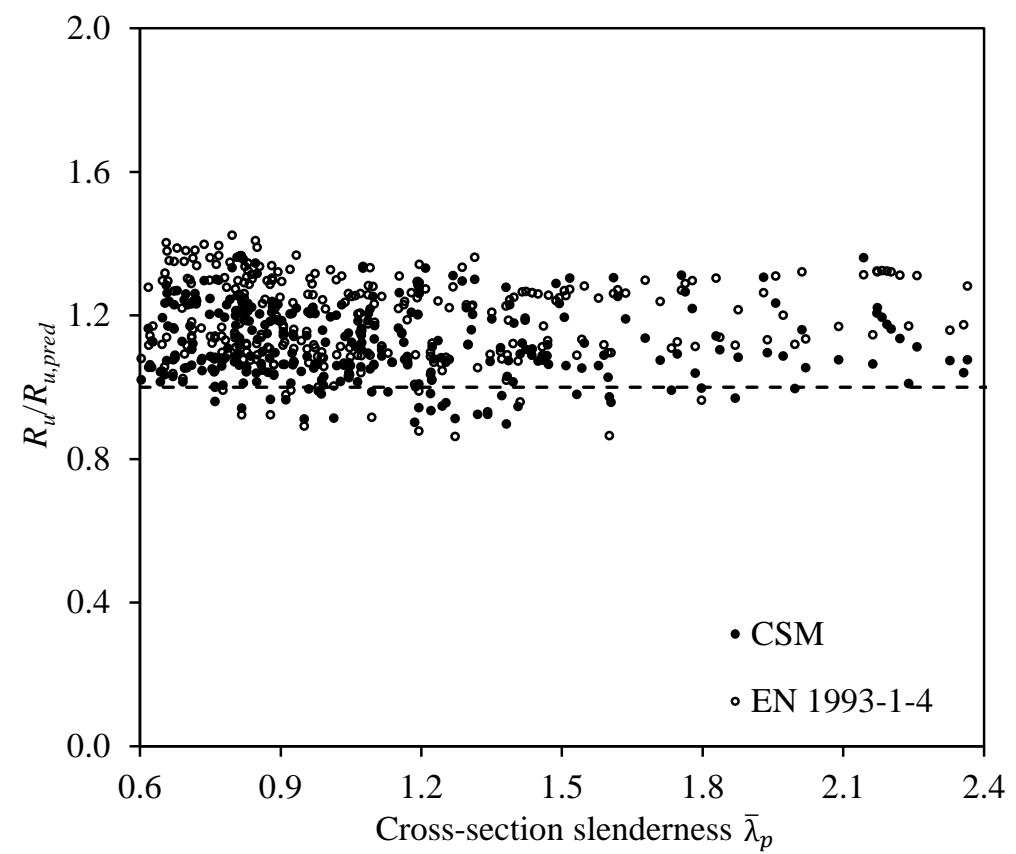

Fig. 9. Comparison of austenitic stainless steel test and FE results with CSM and EN 1993-1-4 strength predictions.

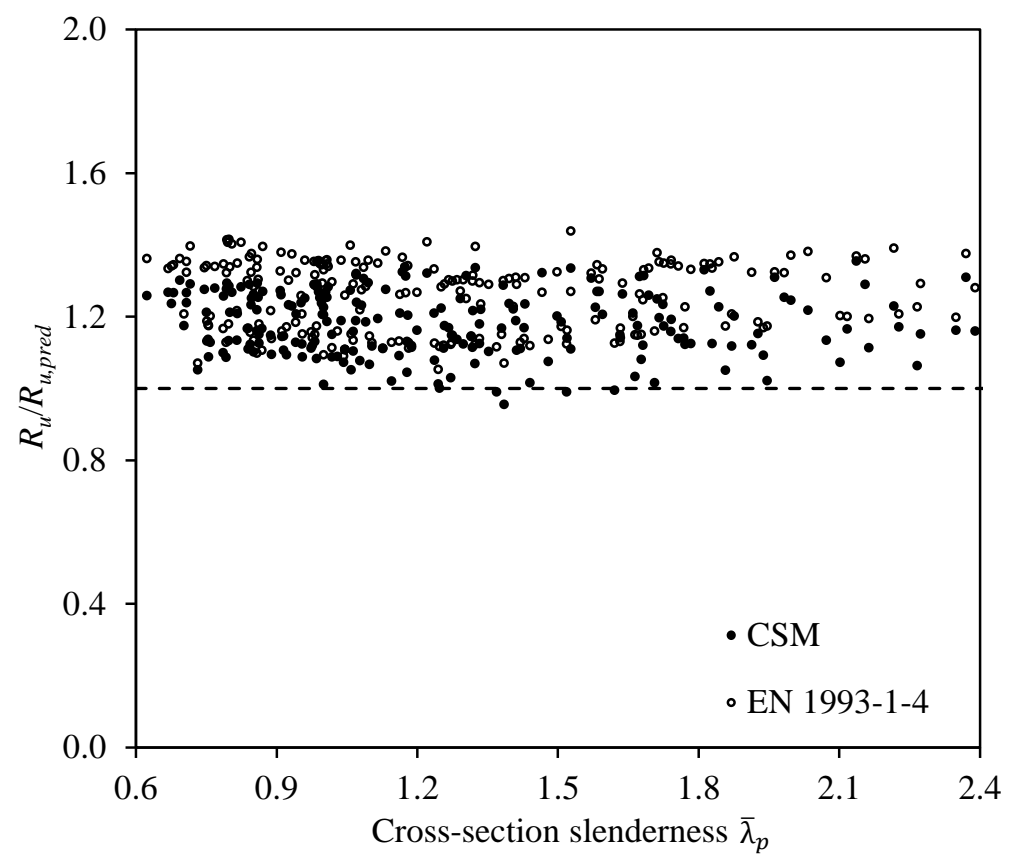

Fig. 10. Comparison of duplex stainless steel test and FE results with CSM and EN 1993-1-4 strength predictions. 


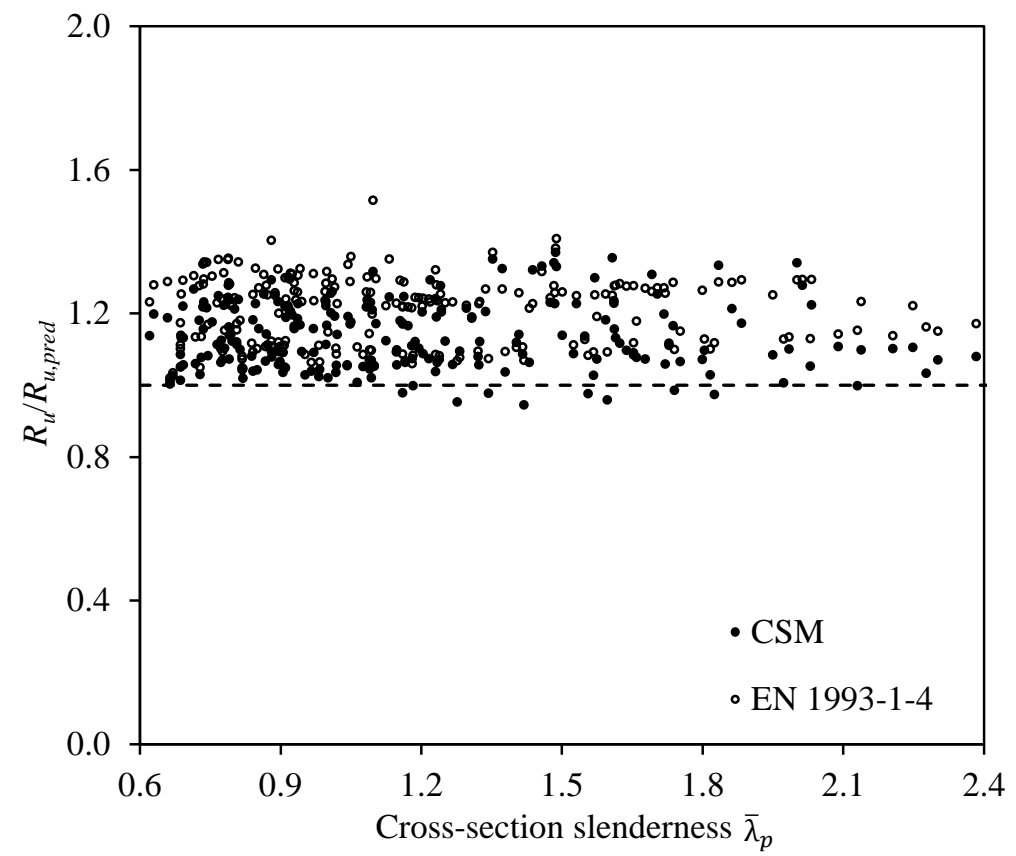

Fig. 11. Comparison of ferritic stainless steel test and FE results with CSM and EN 1993-1-4 strength predictions.

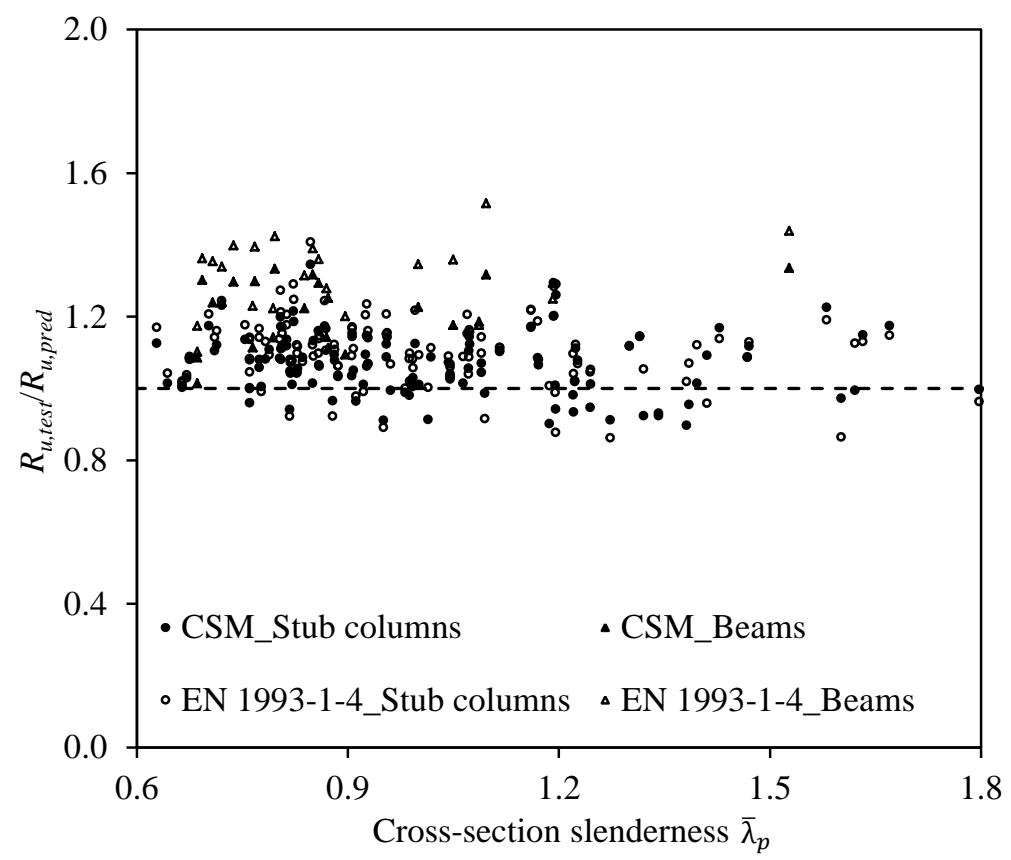

Fig. 12. Comparison of test results with CSM and EN 1993-1-4 resistance predictions. 